\title{
Feasibility of LifeFul, a relationship and reablement-focused culture change program in residential aged care
}

\author{
Lee-Fay Low ${ }^{1 *}$ D, Shruti Venkatesh', Lindy Clemson ${ }^{1}$, Dafna Merom² ${ }^{2}$ Anne-Nicole Casey ${ }^{3}$ and Henry Brodaty ${ }^{3}$
}

\begin{abstract}
Background: The protective, custodial, task-oriented care provided in residential aged care facilitates decreases health and wellbeing of residents. The aim of the study was to conduct a feasibility study of LifeFul - a 12 month reablement program in residential aged care.

Methods: LifeFul was developed based on systematic reviews of reablement and staff behaviour change in residential aged care, and in consultation with aged care providers, consumers and clinicians. LifeFul includes: engaging and supporting facility leaders to facilitate organisational change, procedural changes including dedicated rostering, assigning each resident a 'focus' carer and focusing on the psychosocial care of residents part of handovers and staff training. The study was conducted in three Australian residential aged care facilities. A pre-post mixed methods design was used to evaluate recruitment and retention, fidelity and adherence, acceptability, enablers and barriers and suitability of outcome measures for the program.
\end{abstract}

Results: Eighty of 146 residents agreed to participate at baseline and 69 of these were followed up at 12 months. One hundred and four of 157 staff participated at baseline and 85 of 123 who were still working at the facilities participated at 12 months. Staff perceived the program to be acceptable, barriers included having insufficient time, having insufficient staff, negative attitudes, misunderstanding new procedures, and lack of sufficient leadership support. Quantitative data were promising in regards to residents' depression symptoms, functioning and social care related quality of life.

Conclusion: It is feasible to deliver and evaluate LifeFul. The program could be improved through increased leadership training and support, and by focusing efforts on residents having a 'best week' rather than on completing a document each handover.

Trial registration: Registered prospectively on 22nd January 2016 on ANZCTR369802.

Keywords: Nursing home, Residential aged care, Long-term care, Reablement, Restorative care, Relationship-focused care, Person-centred care

\section{Background}

The protective, custodial and task-oriented model of care provided in residential aged care has been reported to have a deleterious impact on aged care residents, including excessive disability, poor self -care [1,2], functional decline, decreased physical activity and deconditioning [3]. In contrast, reablement or restorative models of care focuses on the restoration and/or maintenance of function

\footnotetext{
*Correspondence: lee-fay.low@sydney.edu.au

${ }^{1}$ The University of Sydney, Sydney, NSW 2006, Australia

Full list of author information is available at the end of the article
}

and helps older adults to compensate for impairments with ageing or illness [4]. Restorative care sets each person a specific goal or desired outcome, such as adapting to some functional loss, or regaining confidence and capacity to resume past activities. There is a growing body of evidence that reablement/restorative care practices in residential aged care improve residents' physical condition and social functioning (e.g. [5-13]).

Preferences of older people support a reablement approach and relationship-focused model of care. Residents have stated that relating to staff is one of the most important aspects of the care they receive [14] and want staff who 
build relationships with them and their families. Further, residents would like opportunities for rehabilitation, mobility and physical exercise, social interaction and engagement in meaningful leisure activities [15].

Aged care policy has begun to emphasize reablement approaches. Reablement approaches are being trialed in the UK, Netherlands and New Zealand [16]. The Australian Productivity Commission recommended that older Australians receive a flexible range of care and support services that meet their individual needs and that emphasize reablement and rehabilitation [17]. The Commonwealth Home Support Program also has a focus on wellness, reablement and restorative care and seeks to actively promote independence [18].

Successful reablement program components identified in the literature include establishing a new philosophy of care $[4,19]$, setting individual goals with residents or clients [19-22], and taking a multidisciplinary approach and providing ongoing training, team meetings and supervision to reinforce the approach on a daily basis [22]. One of the main challenges to susccessfully implementing programs has been compliance by staff [6].

The aims of this paper are to describe the development and components of reablement program for residential aged care - LifeFul; and conduct a feasibility study of the evaluation of LifeFul examining recruitment and retention; fidelity and adherence; acceptability, enablers and barriers; and suitability of outcome measures.

\section{Methods}

\section{LifeFul intervention development}

LifeFul was developed based on the MRC framework for the development of complex interventions [23]. The main steps were:

a) Identification of the evidence base through

(i) A literature review of reablement programs In summary, most randomized controlled trials demonstrated that reablement programs were successful in improving care recipient's health [5, 7-9] reducing need for care or improving activities of daily living $[11,12]$, and were cost effective [24]. One trial was unsuccessful in reducing risk of death or permanent residential care [10]. Importantly, there have been few trials that have specifically targeted persons with dementia [6, 7]. In one study a reablement program improved overall function for cognitively intact residents but not for those who were cognitively impaired [6]. Reablement to date has focused primarily on physical and daily function but has not emphasized engagement with social and recreational activities to improve quality of life.
There is a need for a reablement program focusing on all aspects of health and/or social care related quality of life and which specifically caters for residents with cognitive impairment and dementia.

(ii) A systematic review of programs to change staff behavior in order to improve resident outcomes in residential aged care [25]. This review could not identify any intervention component, or combination of components targeting staff, which was more likely to result in improvement in outcomes in residents, it did however show that the few studies that used theory as part of program design was more likely to be successful in improving resident outcomes.

b) Identification of relevant theory such as through a review of organization change literature such as fundamental principles in organizational change management in implementing effective changes [26, 27].

c) Developing and describing the intervention.

A workshop was conducted with consumers, aged care providers, clinicians and academics to identify important elements and components of a sustainable reablement focused model of care. Initial meetings and ongoing discussions were undertaken with the leadership teams at participating facilities, senior executives and staff regarding program design and implementation.

\section{Components of LifeFul}

The program logic for LifeFul was developed based on a) b) and c) above and is shown in Fig. 1.

The aims of the program are to improve social-care related quality of life and increase person-centred approaches to care by supporting staff to better engage with residents and be more individualized and enabling during social, physical, recreational and daily activities. By improving engagement of residents, we think that residents will experience better overall quality of life, as well as increased, physical and daily function, mood and wellbeing, and decreased agitation. In addition, staff will experience greater work satisfaction and improvement in delivering person-centred care. The philosophy underpinning the intended staff behaviour was person-centred care. Person-centred care in dementia care aims to maintain and nurture 'personhood' in dementia recognising the person's identity, preferences and individual circumstances [28]. Person-centred care improves the quality of life of aged care residents [29]. Bandura's social learning model and Kotter's eight-step model for change were the key theories underpinning staff behaviour change $[27,30]$. 


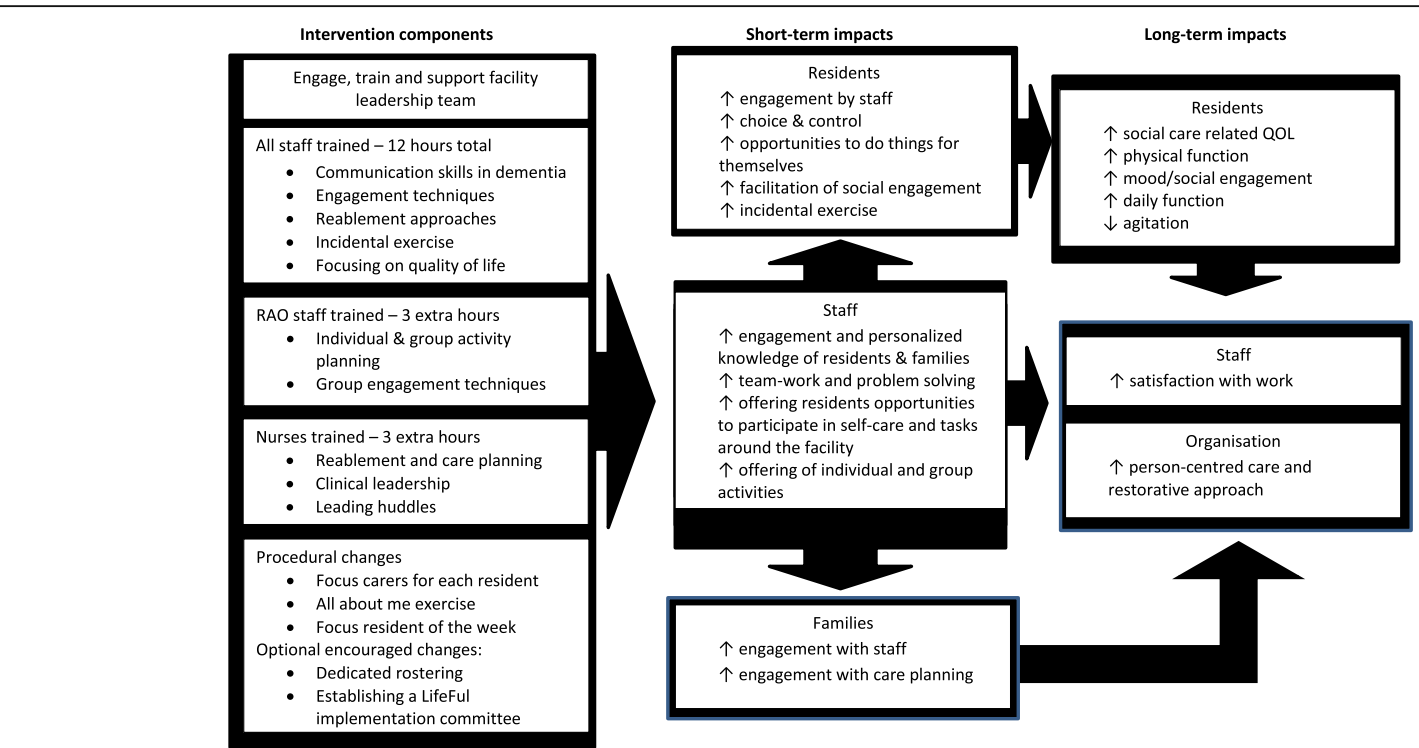

Fig. 1 Lifeful program logic

\section{Engagement and supporting facility managers}

The literature suggests that facility leadership has a key role in changing aged care workplace culture and in research projects [31]. Facility leaders (managers and deputy managers) were engaged and supported to facilitate organizational change.

Researchers met with facility managers and their leadership teams before LifeFul commenced at each site to discuss the program, and to understand needs and challenges at each site. The program was tailored to each site (e.g. one site had a psychosocial history sheet already; we adapted this rather than introducing a new form). Monthly tele-conferences with each site throughout the 12 months program helped monitor progress and barriers which were jointly addressed by the team. For instance, one site asked for an organization-endorsed list of activities around the home which residents were "allowed" to do, as there were misperceptions that policies existed that prevented residents from engaging should not be involved in housekeeping activities (e.g. setting tables). At another site staff struggled to execute the focus resident of the week (handover procedure). Based on feedback the handover form and procedure were changed substantively and reintroduced at the following training session.

\section{Focus Carers and dedicated rostering}

Each resident was allocated to a staff member (focus carer) who had a minimum of three shifts per week. The facility manager and leadership team aimed to match the focus carer with each resident based on the resident's preferences, interests, gender, religion or cultural background and clinical care needs. The role of a focus carer was to specifically develop a good relationship with their focus resident, to get to know them and their social and activities needs. They were encouraged to get to know the resident's family and friends, and work with them collaboratively to improve their resident's quality of life; as well as advocate for the residents during handovers, case conferences, family meetings and care planning. This did not preclude all other staff from getting to know the resident.

There is some evidence that consistent assignment can improve staff-resident relationships and some clinical outcomes [32]. In two facilities, dedicated rostering was implemented. This involved rostering the same group of care staff consistently within the same geographical unit that consisted of between 12 and 20 residents in the facility. Consistent rostering allowed staff and residents to get to know each other better, and for staff to work as a team. In the third facility, one unit already had dedicated rostering, the remaining two units continued to rotate staff across units.

\section{All about me}

The purpose of the All About Me document was to facilitate staff getting to know their residents better. Focus carers were trained to obtain a brief psycho-social history of their resident and then collaborate with the residents to complete a visual representation of their resident's social and activities needs and to set achievable goals (see Additional file 1: Appendix A for a fictitious example). These documents were placed within resident's rooms (e.g. inside their wardrobe doors) and copies were easily accessible in staff rooms. 


\section{Handovers - Focus resident of the week}

Focus residents of the week were introduced to improve team communication about residents' psychosocial needs, focus on quality of life and clinical care, and to reinforce reablement and relationship-focused practices.. Facility managers selected a resident to focus on each week. Care teams set goals based on the resident's goals relating to recreational, physical, and independence promoting activities so that residents had their 'Best Week' possible. Teams were to discuss the focus resident of the week briefly during every handover to ensure that every staff member got to know the resident better and contributed to implementing goals.

\section{Staff training}

All staff were provided with four, three-hour training sessions (12 h in total) over a period of 12 months, with sessions spaced 3 months apart (See Additional file 1: Appendix B). The training program was developed to be interactive, experiential and to support engagement with residents and introduce a reablement approach. As part of these $12 \mathrm{~h}$, activity officers received discipline specific training on tailoring individual and group activities and lifestyle leadership, and nurses received discipline specific training on reablement and planning, clinical leadership and leading handovers.

Training sessions focused on the following:

- Session One - understanding resident's psychosocial history and needs, goal setting, tailored approaches to care and activity engagement particularly for people with dementia, communication skills and completing the All About Me.

- Session Two - reablement approaches, creating opportunities to exercise choice and control, friendships and community in aged care, dementia and behaviour and focus resident of the week.

- Session Three - incidental exercise, reinforcement of skills from previous sessions, and staff self-care.

- Session Four - music, play and sustaining LifeFul.

To accommodate staff from various shifts attending the training program each session was run multiple times (Session 1 ran 9 times, Session 2 ran 11 times, Session 3 ran 9 times, and Session 4 ran 8 times).

\section{Feasibility study}

This is the next phase of complex intervention development according to MRC guidelines.

\section{Evaluation}

The study has been approved by the University of Sydney's Ethics Committee (2015/910) and is registered with the Australian New Zealand Clinical Trials Registry (ACTRN12616000070437).

\section{Setting}

The feasibility of LifeFul was evaluated within three aged care facilities in regional and metropolitan New South Wales, in two facilities we worked with the whole facility, in one facility we worked in three of six units. To be eligible facilities has to be government accredited, not enrolled in another intervention study and executive leadership and site leadership has to be willing to participate. The program was rolled out at unit level within facilities as it was not feasible to implement systemic practice change with some residents, so all residents were included in the intervention.

\section{Study participants and recruitment processes}

Staff recruitment LifeFul training and practice change was mandatory for all care staff (i.e., care staff, registered and enrolled nurses (RNs and ENs), activity officers, allied health and managers) who worked on units in which LifeFul was implemented. Staff were reimbursed for attending training. However, participation in the evaluation was voluntary. Staff who joined the facility after baseline were invited to subsequent training and to participate in the evaluation at 12 months. Information about the study and consent forms were given to staff by the facility manager.

Resident recruitment Residents and their families were informed about the program through posters, an information session and individual letters, and discussion at resident and family meetings. All permanent residents in participating facilities or units were invited to participate in the evaluation of the program $(N=146)$. Information statements and consent forms were given to residents or posted to the person responsible by the facility manager. Written consent was sought from residents where possible. When the resident was not able to provide written consent due to cognitive or mental health related impairments, verbal consent was sought and written consent was obtained from their person responsible. We anticipated that $50 \%$ of 146 residents (i.e., $N=73$ ) would consent to the evaluation of the program.

Residents who entered facilities and units after the commencement of the program were not recruited into the evaluation component.

\section{Design}

The evaluation used a within group pre-post intervention design. Mixed methods were used with quantitative and qualitative data collected. Evaluation occurred at 0 and 12 months for all sites. 


\section{Outcomes}

Recruitment and retention The number of staff and residents agreeing to participate in the study from those eligible within participating facilities were recorded. The number and reasons for dropouts from the study were also recorded.

Fidelity and adherence The number of staff who attended each training (and those who did not) and training components delivered during training were recorded. An audit was conducted of whether each resident was allocated a Focus carer, completion rates of resident's All About Me and resident of the week.

Acceptability, enablers and barriers These were determined through evaluations completed by staff at the end of each training session, monthly tele-conferences with leadership teams, and focus groups and interviews at 12 months with staff and managers.

Suitability of quantitative measures Outcome measures for residents and staff are listed in Table 1.

Data analyses SPSS software was used for analyses. Descriptive statistics were produced for resident and staff demographics, recruitment and retention, fidelity and adherence and quantitative measures. Quantitative measures were examined for ceiling and floor effects, and completion rates. Multilevel linear models were used to examine the change in outcomes between baseline and 12 months. These models take into account correlations between repeated measures. These analyses took an intention-to-treat approach, as multilevel linear models can handle missing data at different time points.

In order to examine acceptability, enablers and barriers we utilized qualitative content analysis [33] to analyze exit interviews, focus groups and meeting minutes. All these data were transcribed. Based on the transcriptions, one author (SV) systematically coded recurrent themes, these were checked by a second author (LFL) and discrepancies resolved through discussion.

\section{Results}

\section{Recruitment and retention of residents and staff}

All 146 residents living at baseline in the selected units were approached to be part of the evaluation of the program and 80 residents $(54.8 \%)$ consented to participate. Resident demographic information is presented in Table 2. At 12 months, 11 (13.8\%) residents were deceased, we were collect dataed from informants on the remaining $69(86.3 \%)$ residents however were only able to interview $67(83.8 \%)$ residents due to increased cognitive impairment.
A total of 157 staff were approached to be part of the evaluation at baseline and 104 staff (66.2\%) participated at baseline. At 12 months, 123 of these staff were still working at these facilities and $85(81.7 \%$ of baseline participants) participated in the evaluation. We did not manage to collect data on how many new staff joined the program through the year, however 36 additional staff participated at 12 months. A total of 140 staff participated in the evaluation over the year. Staff demographics are presented in Table 3.

\section{Fidelity and adherence}

All residents who consented to participate in the evaluation process of the study were allocated a focus carer. Sixty-nine residents (86.3\%) had an All About Me completed. All About Me's were not completed because some residents did not want them (2.5\%) and some staff members had not completed them for their allocated resident $(3.75 \%)$.

Thirty-six residents (45\%) had been focus resident of the week. Reasons that resident's had not been focus residents of the week were that some staff did not understand how to complete the procedure, and the handovers were not scheduled and implemented by facilities' leadership teams.

The attendance of eligible staff at each session was: session $1-88 \%$ (110 of 125), session $2-61.79 \%$ (76 of 123), session $3-87.80 \%$ (108 of 123) and session $4-76.07 \%$ (89 of 117). Staff missed training due to illness, annual leave, forgetting, not knowing about training and having to cover for direct care staff.

\section{Acceptability, barriers and enablers Acceptability - Post training session evaluations}

The majority of staff described the training material as easy to understand (99.28\%), relevant to their workplace (99.28\%) and the training helped with understanding (97.12\%). Written comments suggested that staff enjoyed the activities and most of the content, however found a few concepts difficult to understand (e.g. Maslow's hierarchy of needs, basic task analysis, stages of dementia).

\section{Acceptability - Exit interviews and focus groups}

Interviews and focus groups suggested that staff found the program acceptable, many staff describing benefits of the program. Staff said that LifeFul helped them to build better relationships with residents by taking time to get to know them, listening to them, and relating to them on a personal level. This led to increased understand the residents' behaviors and needs.

"Being able to have closer insight into the client and better understanding of why people do the things they do and why, they react differently with different staff" 
Table 1 Outcome Measures for Residents and Staff

\begin{tabular}{|c|c|c|c|c|c|c|c|}
\hline \multirow[t]{2}{*}{$\overline{\text { Data }}$} & \multirow[t]{2}{*}{ Instrument } & \multirow[t]{2}{*}{ Descriptor } & \multicolumn{3}{|c|}{ Completed By } & \multicolumn{2}{|c|}{ Time Point } \\
\hline & & & Resident & Staff & Researcher & $T=0$ & $T=12$ \\
\hline \multicolumn{8}{|c|}{ Resident's Everyday Experiences } \\
\hline $\begin{array}{l}\text { Resident's Autonomy, } \\
\text { Control \& Quality-of-Life }\end{array}$ & $\begin{array}{l}\text { Adult Social Care Outcomes } \\
\text { Toolkit (ASCOT): Care home } \\
\text { interview schedule (CHINT-3); } \\
\text { Care Home Resident Interview } \\
\text { Schedule (CHResidentINT3); } \\
\text { Care Home Observation } \\
\text { Schedule (CHOBS3) [34] }\end{array}$ & $\begin{array}{l}\text { Interview with resident and staff, } \\
\text { and observation. ASCOT measures } \\
8 \text { domains: control of daily life; } \\
\text { personal cleanliness and comfort; } \\
\text { food and drink; personal safety; } \\
\text { social participation and involvement; } \\
\text { occupation; accommodation } \\
\text { cleanliness and comfort; and dignity). } \\
\text { Each domain is scored from } 0 \text { (high } \\
\text { needs) to } 3 \text { (no neeeds) and is } \\
\text { weighted to provide a final current } \\
\text { QOL score. Inter-rater reliability: } \\
r=0.618 \text { ( } p<0.001 \text { ). Internal reliability } \\
\text { Cronbach's alpha = .71(Netten } \\
\text { et al., 2010) }\end{array}$ & $x$ & $x$ & $x$ & $x$ & $x$ \\
\hline $\begin{array}{l}\text { Resident's Social } \\
\text { Engagement }\end{array}$ & $\begin{array}{l}\text { Social Identification and } \\
\text { Satisfaction (SIS) [35] }\end{array}$ & $\begin{array}{l}\text { By interview. SIS measures social } \\
\text { identification and integrity and } \\
\text { consists of } 17 \text { items organized into } \\
\text { three subscales: social identification, } \\
\text { satisfaction with lounge and } \\
\text { satisfaction with life in the home. Each } \\
\text { item is rated from } 1 \text { (completely } \\
\text { disagree) to } 7 \text { (completely agree). } \\
\text { Reliability Cronbach's alpha }=.70 \text {. }\end{array}$ & $x$ & & & $x$ & $x$ \\
\hline Physical Function & $\begin{array}{l}\text { Short Physical Performance } \\
\text { Battery (SPPB) (Guralnik } \\
\text { et al., 1994) [36] }\end{array}$ & $\begin{array}{l}\text { By interview. Battery consists of } 3 \text { tests: } \\
\text { balance test, gait speed test and chair } \\
\text { stand test. ICC }=0.82 \text {; reliability of gait } \\
\text { speed test ICC }=0.79 \text {; reliability of chair } \\
\text { stand test } r=0.80 \text {; reliability of tandem } \\
\text { balance test is low }(r=0.22) \text { (Puthoff, } \\
\text { 2008) }\end{array}$ & $x$ & & & $x$ & $x$ \\
\hline Depression & $\begin{array}{l}\text { Cornell Scale for Depression } \\
\text { in Dementia (Alexopolous } \\
\text { et al., 1988) [37] }\end{array}$ & $\begin{array}{l}19 \text { items rated on severity based on } \\
\text { interview with resident and staff. Each } \\
\text { item is scores from } 0 \text { (absent) to } 2 \\
\text { (severe) and a total score }>7 \text { suggest } \\
\text { high probability of clinical depression. } \\
\text { It has internal consistency Cronbach's } \\
\text { alpha }=0.84 \text {; inter-rater reliability } \\
\text { range: } 0.67-0.74\end{array}$ & $x$ & $x$ & $x$ & $x$ & $x$ \\
\hline Daily function & $\begin{array}{l}\text { Disability Assessment for } \\
\text { Dementia (DAD)(Gelinas } \\
\text { et al., 1999) [38] }\end{array}$ & $\begin{array}{l}\text { Informant-complete: } 40 \text { items which } \\
\text { measures basic activities of daily living, } \\
\text { instrumental activities of daily living } \\
\text { and leisure activities. Each item is } \\
\text { categorized into cognitive dimensions } \\
\text { of initiation, planning and organisation } \\
\text { and effective performance. Each item } \\
\text { can be scored as yes (1), no (0), or not } \\
\text { applicable. Test-retest reliability: .96; } \\
\text { inter-rater reliability: .95 and internal } \\
\text { consistency Cronbach's alpha }=.96 .\end{array}$ & & $x$ & & $x$ & $x$ \\
\hline Agitation & $\begin{array}{l}\text { Cohen-Mansfield Agitation } \\
\text { Inventory (CMAl) } \\
\text { (Cohen-Mansfield, 1989) [39] }\end{array}$ & $\begin{array}{l}\text { By interview: } 29 \text { items measuring } \\
\text { agitated behaviours in elderly person. } \\
\text { Each item is rated on frequency from } \\
1 \text { (never) to } 7 \text { (several times an hour). } \\
\text { Cronbach's alpha } 0.75-0.91 \text { (in different } \\
\text { studies); test-retest r: } 0.79-0.9 \text {; inter- } \\
\text { rater correlations: } 0.76-0.96\end{array}$ & & $x$ & & $x$ & $x$ \\
\hline Satisfaction with Work & $\begin{array}{l}\text { Nursing Home Nurse Aide } \\
\text { Job Satisfaction Questionnaire } \\
\text { (NHNA-JSQ) (Castle et al., } \\
\text { 2007) [40]. }\end{array}$ & $\begin{array}{l}\text { NHNA-JSQ is a } 21 \text { item measure (each } \\
\text { item rated from } 1-\text { very poor to } 10 \text { - } \\
\text { excellent) and has seven subscales - } \\
\text { (1) Coworkers (the relation that the } \\
\text { person has with other workers in the }\end{array}$ & & $x$ & & $x$ & $x$ \\
\hline
\end{tabular}


Table 1 Outcome Measures for Residents and Staff (Continued)

\begin{tabular}{|c|c|c|c|c|c|c|c|}
\hline \multirow[t]{2}{*}{ Data } & \multirow[t]{2}{*}{ Instrument } & \multirow[t]{2}{*}{ Descriptor } & \multicolumn{3}{|c|}{ Completed By } & \multicolumn{2}{|c|}{ Time Point } \\
\hline & & & Resident & Staff & Researcher & $T=0$ & $T=12$ \\
\hline
\end{tabular}

facility), (2) Workplace Support

(resources and demands of the job),

(3) Work Content (the complexity and

challenge of the work), (4) Work

Schedule (time pressures), (5) Training

(preparation required for position, (6)

Rewards (benefits of the job) and (7)

Quality of Care (how well nurse aides

perceive residents are being cared for).

The NHNA-JSQ has good internal

consistency (Cronbach's alpha > .74).

Person-Centred Care Approach
Person-Centered Care Assessment Tool (P-CAT) (Edvardsson et al., 2010) [41]
P-CAT is a13 item measure $(1=$ disagree completely to $5=$ agree completely). The

P-CAT measures the degree to which staff engage in person-centred care and has three subscales - personalising care (the degree to which staff and the organisation adhere to person-centred care), organisational support (the degree to which the organisation supports staff to engage in personcentred care) and environmental accessibility (the degree to which residents can access their immediate environment). The P-CAT has good internal consistency (Cronbach's alpha $=0.84)$ and high retest reliability $(r=.7-.9)$.
"This has given me more understanding about residents on a more personal level - more knowledge how to relate to residents"

Staff also described how LifeFul helped them develop their skills by giving them specific skills in improving their communication and presenting activities.

\section{"Learning new methods to make residents lives happier/better. Fresh ideas.”}

Table 2 Resident Demographics at baseline $(n=80)$

\begin{tabular}{ll}
\hline Variable & Mean (SD, range) or number (\%) \\
\hline Age & $87.6(7.5,63.6-98.8)$ \\
Female & $64(80.0 \%)$ \\
Born Overseas & $9(11.3 \%)$ \\
Marital Status & \\
$\quad$ Single & $9(11.3 \%)$ \\
$\quad$ Widowed & $50(62.5 \%)$ \\
$\quad$ Divorced & $5(6.3 \%)$ \\
$\quad$ Married/Partnered & $16(20 \%)$ \\
Days lived in facility & $1042.8(77 ; 5-3804)$ \\
No of Medical \& Psychological & $8.1(3.2,1-15)$ \\
Diagnoses &
\end{tabular}

Table 3 Staff Demographics $(n=140)$

\begin{tabular}{llr}
\hline Variable & $\begin{array}{l}\text { Mean (SD, range) } \\
\text { or number (\%) }\end{array}$ & N Missing \\
\hline Age & $42.8(12.5,18-67)$ & 13 \\
Female & $124(89 \%)$ & 1 \\
Born in Australia & $115(82 \%)$ & 13 \\
Years of Education & $12.9(2.8,8-21)$ & 73 \\
Highest Education & & 59 \\
School Certificate & $22(15.7 \%)$ & \\
Trade Certificate & $30(21.4 \%)$ & \\
$\quad$ Undergraduate Degree & $28(20.0)$ & \\
$\quad$ Post-Graduate Qualification & $1(0.7 \%)$ & \\
Position at Organisation & & 17 \\
Registered Nurse & $18(12.9 \%)$ & \\
Activity Officer & $11(7.9 \%)$ & \\
Care Staff & $97(69.3 \%)$ & \\
Pastoral Care & $1(0.7)$ & \\
Care Manager & $4(2.9 \%)$ & \\
Kitchen Hand & $5(2.6 \%)$ & \\
Physiotherapist Assistant & $2(1.4 \%)$ & \\
Administrative Staff & $1(0.7 \%)$ & \\
Hours Worked (per week) & $28.2(8.0,10-40)$ & \\
Years working in aged care & $5.5(5.7,0.1-29)$ & \\
facilities & & \\
\hline
\end{tabular}


Staff also reported that LifeFul encouraged them to be more creative and think laterally when solving problems at work.

\section{"Being creative also helps with problem solving which is really important in a dementia unit."}

Staff members noticed positive changes in the units they worked in. Residents were more settled as a consequence of implementing some of the strategies from LifeFul, for instance by increasing family involvement and accepting family as part of the community rather than perceiving them as visitors. Staff began involving residents in the daily tasks of the unit (e.g., cleaning tables, folding clothing protectors, helping to push trolleys).

"The 'All About Me' sheets gave us a starting point. An insight into the resident's personality. What staff initially saw as uncooperative they now saw as proud and independent. Physical outbursts are no longer viewed as unpredictable or malicious. Incidents of hitting rarely happen now, and if they do, we understand why they happened and what our response should be. Staff are building up a level of trust with her and seeing her for who she is, and not just as unmanageable negative behaviors."

\section{Barriers}

Having limited time at work, or a long list of work tasks meant that staff found it difficult to spend time getting to know residents and complete new program procedures.

"Found it stressful, I had two focus residents plus I had to do that and make sure I talked to the families, residents and make sure that I do my work."

When there was a small number of staff on each unit (sometimes only 1) the lack of time seemed to be exacerbated, as staff didn't have team-mates to help solve clinical problems, discuss daily stressors, for motivation and to change the unit atmosphere. This was an issue in low care units.

"If there were more staff, they could be more activities, more social interaction, getting to know the residents. It would also give someone for the care staff to bounce ideas off"

Negative or ambivalent attitudes of staff towards the program were also described as a barrier. Some staff did not see program implementation as their responsibility, did not prioritize or see value in implementing the program, or did not want to change their usual care practices.

"No matter where you go you will have a small amount of people if something new is going to be implemented it's always going to be negative."

Some staff also did not understand the new procedures (All About Me, Best Week Handover), even though they had received training. They were unsure about whose responsibility it was to complete the procedures, as well as the correct way of filling out the documents.

"Some staff suggested more clarity around forms; specifically the handovers as they were interpreted differently to what was initially intended."

Staff found it more difficult implementing the program with residents with later stage dementia. They described it being more difficult to communicate, obtain information, set goals for, and motivate these residents.

In two units where staff were rotated in and out of those areas every 3 months (i.e. where dedicated rostering was not implemented), the program appeared to have the least impact based on staff feedback, even though All About Me sheets and focus resident of the week were completed. Staff found it difficult to spend time with their focus resident when working in a different area, and were not motivated to work on long-term goals for residents as they could be rotated out of that area before being able to meet those goals.

Staff, facility managers and executive managers all commented on the importance of the facility leadership team (manager and unit or deputy managers) in implementing the program. Some staff perceived that the program was not supported sufficiently by their manager. We also observed that the program stalled if facility leadership did not continue to motivate staff and complete administrative and logistical aspects of the program (e.g. assigning focus carers, scheduling timetable of focus residents of the week), as well as role modelling behavior (e.g. attending Best Week handovers).

\section{"Management need to support staff at different stages of building that relationship with carers, such as, starting to do the All About Me sheets, or having a focus resident at handover."}

\section{Enablers}

Specific staff members were described as acting as informal or formal program LifeFul champions. On some units, a key person or persons took their own initiative, in one facility staff were selected by facility managers and asked 
to support their colleagues. These champions facilitated program implementation through organization, education, motivation, resource development (e.g. obtaining materials for activities), and role modelling.

"Thank God for X. She helped me and all of us. If it wasn't for her I wouldn't have finished"

Units where staff were already working well as a team, or where team work and morale improved through LifeFul, reported better success in implementing practices changes beyond the procedural aspects of the program.

Suitability of quantitative measures for residents and staff Residents' scores on the outcomes measures at baseline and 12 months, and the results from multilevel linear models are reported in Table 4. On the Adult Social Care Outcome Toolkits (ASCOT) self-complete component at baseline and 12 months, 66 (82.20\%) and 52 (76.47\%) residents completed them respectively. Some residents did not complete the ASCOT self-complete component because of difficulties with communication and/or comprehension. On the informant component of the ASCOT, we obtained data for 76(95\%) residents at baseline and all 69 (100\%) residents at 12 months. Some staff informants were unable to score domain 1 (control) of the ASCOT at baseline as these residents were non-communicative. The majority of scores on ASCOT domains fell into the No Needs category (80.30-98.50\%), suggesting the possibility of a ceiling effect on this tool.

On the Short Physical Performance Battery (SPPB), 52 $(70.00 \%)$ and $36(53.73 \%)$ participants were able to complete all three subscales at baseline and 12 months, respectively.

Some residents found it difficult to complete the seven-point Likert scale for the Social Identification and Satisfaction Subscale (SIS), we requested those residents respond Yes or No instead. At baseline and 12 months, $57(71.25 \%)$ and $50(74.63 \%)$ participants were able to complete all three subscales on the measure.

We obtained complete data on the three measures that were completed by staff on residents' mood, behavior and daily functioning (i.e., Cornell Depression Scale, Cohen Mansfield Agitation Inventory - CMAI and Disability Assessment for Dementia - DAD) at baseline and 12 months.

Table 4 Resident outcomes at baseline and 12 months

\begin{tabular}{|c|c|c|c|}
\hline Outcome Measure & Baseline $M(S D, N)$ & 12 Months $M(S D, N)$ & $\begin{array}{l}\text { Difference between baseline and } \\
12 \text { months ( } 95 \% \text { confidence interval) }\end{array}$ \\
\hline \multicolumn{4}{|l|}{ Adult Social Care Outcome Toolkit ASCOT } \\
\hline Domain 1 Control & $0.79(0.23, N=76)$ & $0.85(0.21, N=67)$ & $b=-0.05(-0.12$ to 0.01$)$ \\
\hline Domain 2 Personal Hygiene & $0.86(0.14, N=76)$ & $0.88(0.07, N=67)$ & $b=-0.02(-0.04$ to 0.01$)$ \\
\hline Domain 3 Food & $0.79(0.19, N=76)$ & $0.80(0.18, N=67)$ & $b=-0.02(-0.08$ to 0.04$)$ \\
\hline Domain 4 Safety & $0.69(0.10, N=76)$ & $0.72(0.00, N=67)$ & $b=-0.03(-0.05$ to -0.01$)$ \\
\hline Domain 5 Social Participation & $0.72(0.17, N=76)$ & $0.76(0.15, N=67)$ & $b=-0.04(-0.07$ to 0.00$)$ \\
\hline Domain 6 Occupational Engagement & $0.79(0.20, N=76)$ & $0.85(0.18, N=67)$ & $b=-0.05,(-0.11$ to 0.00$)$ \\
\hline Domain 7 Accommodation & $0.85(0.05, N=76)$ & $0.86(0.00, N=67)$ & $b=-0.01(-0.17$ to 0.06$)$ \\
\hline Domain 8 Dignity & $0.75(0.12, N=76)$ & $0.78(0.00, N=67)$ & $b=-0.03(-0.54$ to -0.01$)$ \\
\hline ASCOT Total (SCRQoL) & $0.84(0.17, N=76)$ & $0.89(0.12, N=67)$ & $b=-0.05,(-0.08$ to -0.02$)$ \\
\hline \multicolumn{4}{|l|}{ Short Physical Performance Battery (SPPB) } \\
\hline Balance Test Total Score & $1.63(1.05, N=52)$ & $1.81(1.09, N=36)$ & $b=0.07(-0.20$ to 0.34$)$ \\
\hline Gait Test Total Score & $2.40(0.95, N=52)$ & $2.64(0.90, N=36)$ & $b=0.06(-0.24$ to 0.35$)$ \\
\hline Repeated Chair Stand Score & $0.67(1.06, N=52)$ & $0.81(1.14, N=36)$ & $b=0.12(-0.17$ to 0.42$)$ \\
\hline \multicolumn{4}{|l|}{$\begin{array}{l}\text { Social Identification and Satisfaction } \\
\text { Subscale (SIS) }\end{array}$} \\
\hline Social Identification & $4.36(0.96, N=57)$ & $4.30(0.86, N=50)$ & $b=0.04(-0.27$ to 0.35$)$ \\
\hline Satisfaction with Lounge & $4.79(1.52, N=57)$ & $4.54(1.34, N=50)$ & $b=0.26(-0.18$ to 0.70$)$ \\
\hline Satisfaction with Life in the Home & $3.67(0.72, N=57)$ & $3.66(0.75, N=50)$ & $b=0.11(-0.20$ to 0.42$)$ \\
\hline Cornell Depression Total & $7.12(7.91, N=80)$ & $4.49(4.30, N=67)$ & $b=2.28$ (0.77 to 3.79$)$ \\
\hline $\begin{array}{l}\text { Cohen Mansfield Agitation Inventory } \\
\text { (CMAI) Total }\end{array}$ & $40.94(14.31, N=80)$ & $40.76(16.32, N=67)$ & $b=-0.32(-3.74$ to 3.10$)$ \\
\hline $\begin{array}{l}\text { Disability Assessment for Dementia } \\
\text { (DAD) Total }\end{array}$ & $41.46(27.45, N=80)$ & $50.83(32.96, N=67)$ & $b=-2.15(-10.61$ to -0.38$)$ \\
\hline
\end{tabular}


Staff scores on the outcomes measures at baseline and 12 months, and the results from multilevel linear models are reported in Table 5. On the Nursing Home Nurse Aide Job Satisfaction Questionnaire (NHNA-JSQ) 104 (66.24\%) and 95(77.24\%) staff completed the outcome measure at baseline and 12 months, respectively. On the Person-Centered Care Assessment Tool (P-CAT), 98 (62.42\%) and $95(77.24 \%)$ staff completed the outcome measure at baseline and 12 months, respectively. Fewer staff completed the P-CAT than the NHNA-JSQ at baseline due to a procedural error in filling out the evaluation form.

\section{Changes over time}

There was a reduction in residents' depression symptoms (Cornell Depression), improved functioning (Disability Assessment for Dementia Scale) and improvement in the ASCOT domains of safety, occupational engagement, dignity and overall quality of life (ASCOT SCRQoL). There were no differences between baseline and 12 months on the SPPB Subscales, SIS subscales or the CMAI. See Table 4.

There were no changes over time on any of the staff outcome measures. See Table 5.

\section{Discussion}

This study demonstrated that it is feasible to implement and evaluate LifeFul, a reablement and relationship-focused program to change staff care practices in residential aged care facilities. LifeFul changed some staff care practices and produced promising improvements in resident outcomes. However, there were challenges in implementation. Less than $80 \%$ of staff attended training. In the future we would work more closely with facility managers to ensure that mandatory training attendance was policed, that staff were given sufficient notice about training dates, and that staff were not pulled out of training to back fill for staff on leave. The original format for focus resident of the week handovers had low acceptability. We changed these so that care teams spent 1 week gathering information about residents and setting goals, and then wrote a psychosocial care plan the following week. LifeFul required ongoing motivation of staff, this might be achieved by better preparing and supporting the facility leadership team to lead the change required in the program, as well as appointing staff champions to assist with administration, execution and motivation.

There may be a ceiling effect on the proposed primary outcome measure of social care related quality of life (the ASCOT) which makes it less sensitive to changes as a consequence of the program. We identified no other suitable measure of social-care related quality of life in residential care. Increasing the scale of ASCOT items may minimize this ceiling effect, this is currently being tested by the research team that developed the scale. The ceiling effect may reflect the high quality of care provided in participating facilities, and may not be representative of Australian residential care facilities.

Strengths of this study are that we worked with organizations which supported the procedural changes required in LifeFul, the research team worked closely with facility management to monitor implementation and clarified, adapted and supported as needed. The training component was commended by staff as being interactive and engaging.

This feasibility study was not designed to produce generalizable results. Our small sample came from a non-representative group of three volunteer residential aged care facilities, all in regional areas with low proportions of residents from culturally and linguistically diverse backgrounds, and relatively low staff turnover

Table 5 Staff Outcomes at baseline and 12 months

\begin{tabular}{|c|c|c|c|}
\hline Outcome Measure & Baseline $M(S D, N)$ & 12 Months $M(S D, N)$ & $\begin{array}{l}\text { Difference between baseline and } \\
12 \text { months ( } 95 \% \text { confidence interval) }\end{array}$ \\
\hline \multicolumn{4}{|c|}{ Nursing Home Nurse Aide Job Satisfaction Questionnaire (NHNA-JSQ) } \\
\hline Co-Workers & $7.64(1.76,104)$ & $7.73(1.57,95)$ & $b=-0.22(-0.56$ to 0.12$)$ \\
\hline Workplace Support & $7.36(1.44,104)$ & $7.62(1.56,95)$ & $b=-0.27(-0.61$ to 0.06$)$ \\
\hline Work Content & $8.76(1.05,104)$ & $8.76(1.05,95)$ & $b=-0.01(-0.25$ to 0.26$)$ \\
\hline Work Schedule & $7.29(1.61,104)$ & $7.38(1.66,95)$ & $b=-0.14,(-0.56$ to 0.28$)$ \\
\hline Training & $8.17(1.31,104)$ & $7.98(1.60,95)$ & $b=0.14(-0.18$ to 0.49$)$ \\
\hline Rewards & $6.19(2.25,104)$ & $6.10(2.28,95)$ & $b=0.08(-0.35$ to 0.50$)$ \\
\hline Quality of Care & $8.58(1.13,104)$ & $8.64(1.19,95)$ & $b=-0.13(-0.38$ to 0.13$)$ \\
\hline Global Ratings & $8.24(1.53,104)$ & $7.96(1.84,95)$ & $b=0.19(-0.18$ to 0.56$)$ \\
\hline \multicolumn{4}{|c|}{ Person-Centered Care Assessment Tool (P- CAT) } \\
\hline Personalising Care & $3.69(0.75,98)$ & $3.79(0.80,95)$ & $b=-0.13(-0.30$ to 0.05$)$ \\
\hline Organisational Support & $2.76(0.86,98)$ & 2. $69(0.83,95)$ & $b=0.06(-0.18$ to 0.28$)$ \\
\hline Environmental Accessibility & $3.18(0.92,98)$ & $3.17(0.87,95)$ & $b=-0.01(-0.22$ to 0.20$)$ \\
\hline
\end{tabular}


(16.20\% across two sites from the same organization). The pre-post uncontrolled design means that we cannot be certain that our intervention had a causal impact on observed resident outcomes. We also did not correct for multiple comparisons, or control for age, gender or other characteristics.

\section{Conclusions}

In conclusion, these results suggest that it is feasible to deliver and evaluate LifeFul. A fully-powered controlled trial, including an economic analysis, is required to see if the program can improve resident outcomes.

\section{Additional file}

Additional file 1: Appendix A: Fictitious sample of All About Me sheet and Appendix B: Description of LifeFul training program. (DOCX 603 kb)

\section{Abbreviations}

ASCOT: Adult social care outcome toolkits; CDS: Cornell depression scale: CMAl: Cohen mansfield agitation inventory; DAD: Disability assessment for dementia; EN: Enrolled nurses; NHNA-JSQ: Nursing home nurse aide-job satisfaction questionnaire; P-CAT: Person-centered care assessment tool; RN: Registered nurses; SIS: Social identification and satisfaction subscale; SPPB: Short physical performance battery

\section{Acknowledgements}

We would like to thank residents, families, staff and leadership teams from the Whiddon Group and Catholic HealthCare for their support and participation.

\section{Funding}

This study was funded by a NHMRC Career Development Fellowship, and through funds from the Centre for Healthy Brain Ageing and The Whiddon Group. The NHMRC had no role in design of the study and collection, analysis, and interpretation of data and in writing the manuscript. Prof Brodaty is co-director of the Centre for Healthy Brain Ageing and was involved in design of the study, in writing the manuscript. The Whiddon Group assisted with data collection. The funding bodies did not have place any restrictions on the publication of results.

\section{Availability of data and materials}

The datasets used and/or analysed during the current study are available from the corresponding author on reasonable request.

\section{Authors' contributions}

LFL, LC, DM, ANC and HB conceptualized the study and obtained funding. All authors contributed to intervention development. LFL and SV conducted data analysis and drafted the manuscript. All authors contributed to the paper. All authors read and approved the final manuscript.

\section{Authors' information}

Lee-Fay Low is Associate Professor in Health and Ageing at the University of Sydney (Sydney, Australia). She is a registered psychologist with a PhD in psychiatric epidemiology.

Shruti Venkatesh is a clinical psychologist with a PhD in cognitive and clinical psychology. She works clinically in chronic pain management and has worked on research in the areas of aged care, eating disorders and ethics in professional psychology.

Lindy Clemson is Professor in Ageing and Occupational Therapy at the University of Sydney and holds a PhD in epidemiology. Her expertise is in falls prevention and programs she has developed such as "Stepping On" have been implemented around the world.

Dafna Merom is Professor of Physical Activity and Health at the School of Science and Health at Western Sydney University. She has research expertise in physical activity/exercise engagement and quality of life of older people.
Anne-Nicole Casey is a post-doctoral researcher with a PhD in Psychiatry. She has research expertise in friendship and social relationships in residential aged care, and direct observation of human and non-human animal behaviour.

Henry Brodaty is Scientia Professor of Ageing and Mental Health at University of New South Wales, Co-Director of the Centre for Healthy Brain Ageing and Director of the Dementia Centre for Research Collaboration. He has expertise in assessment and clinical aspects of dementia, behavioural and psychological symptoms of dementia, interventions for family carers, nursing home research, and prevention of cognitive decline and Alzheimer's disease.

\section{Ethics approval and consent to participate}

This study was approved by the University of Sydney Human Research Ethics Committee (2015/910). All participants provided written consent before participating in the study.

\section{Competing interests}

Prof Merom is a member of the BMC Geriatrics Editorial Board. The other authors have declare no potential conflicts of interest with respect to the research, authorship, and/or publication of this article.

\section{Publisher's Note}

Springer Nature remains neutral with regard to jurisdictional claims in published maps and institutional affiliations.

\section{Author details}

${ }^{1}$ The University of Sydney, Sydney, NSW 2006, Australia. ${ }^{2}$ Western Sydney University, Campbelltown, Sydney, NSW 2560, Australia. ${ }^{3}$ Centre for Healthy Brain Ageing (CHeBa), the University of New South Wales, Sydney, NSW 2052, Australia.

Received: 18 December 2017 Accepted: 22 May 2018

Published online: 31 May 2018

\section{References}

1. Rogers JC, Holm MB, Burgio LD, Hsu C, Hardin JM, McDowell BJ. Excess disability during morning care in nursing home residents with dementia. Int Psychogeriatr. 2000;12(2):267-82.

2. Osborn $\mathrm{CL}$, Marshall MJ. Self-feeding performance in nursing home residents. J Gerontol Nurs. 1993;19(3):7-14.

3. Resnick B, Galik E, Boltz M. Function focused care approaches: literature review of progress and future possibilities. J Am Med Dir Assoc. 2013, 14(5):313-8

4. Galik EM, Resnick B. Restorative care with cognitively impaired older adults: moving beyond behavior. Topics in Geriatric Rehabilitation. 2007:23(2):114-25.

5. Johnson CSJ, Myers AM, Jones GR, Fitzgerald C, Lazowski DA, Stolee P, Orange JB, Segall N, Ecclestone NA. Evaluation of the restorative care education and training program for nursing homes. Canadian Journal on Aging. 2005:24(2):115-26.

6. Kerse N, Peri K, Robinson E, Wilkinson T, Von Randow M, Kiata L, Parsons J, Latham N, Parsons M, Willingale J, et al. Does a functional activity programme improve function, quality of life, and falls for residents in long term care? Cluster randomised controlled trial. BMJ. 2008;337(7675):912-5.

7. Galik E, Resnick B, Hammersla M, Brightwater J. Optimizing function and physical activity among nursing home residents with dementia: testing the impact of function-focused care. The Gerontologist. 2014;54(6):930-43.

8. Parsons JGM, Sheridan N, Rouse P, Robinson E, Connolly M. A randomized controlled trial to determine the effect of a model of restorative home care on physical function and social support among older people. Arch Phys Med Rehabil. 2013;94(6):1015-22

9. King A, Parsons M, Robinson E, Jörgensen D. Assessing the impact of a restorative home care service in New Zealand: a cluster randomised controlled trial. Health and Social Care in the Community. 2012;20(4):365-74

10. Senior HEJ, Parsons M, Kerse N, Chen MH, Jacobs S, Hoorn SV, Anderson CS Promoting independence in frail older people: a randomised controlled trial of a restorative care service in New Zealand. Age Ageing. 2014;43(3):418-24.

11. Lewin G, De San Miguel K, Knuiman M, Alan J, Boldy D, Hendrie D, Vandermeulen S. A randomised controlled trial of the home independence program, an Australian restorative home-care programme for older adults. Health Soc Care Community. 2013;21(1):69-78. 
12. Tinetti ME, Baker D, Gallo WT, Nanda A, Charpentier P, O'Leary J. Evaluation of restorative care vs usual care for older adults receiving an acute episode of home care. J Am Med Assoc. 2002;287(16):2098-105.

13. Tuntland H, Aaslund MK, Espehaug B, Førland O, Kjeken I. Reablement in community-dwelling older adults: a randomised controlled trial Physical functioning, physical health and activity. BMC Geriatr. 2015;15(1):145.

14. Bowers BJ, Fibich B, Jacobson N. Care-as-Service, Care-as-Relating, Care-ascomfort: understanding nursing home Residents' definitions of quality. The Gerontologist. 2001;41(4):539-45.

15. Jeon Y-H, Forsyth R. Quality Domains for the Development of a Consumer Focused Report on Quality of Residential Aged Care. Sydney Nursing School, The University of Sydney: Camperdown; 2016.

16. Aspinal F, Glasby J, Rostgaard T, Tuntland H, Westendorp RCJ. New horizons: Reablement - supporting older people towards independence. Age Ageing. 2016:45(5):574-8.

17. Productivity Commission. Caring for Older Australians. Canberra: Productivity Commission; 2011.

18. Department of Health: Living well at home: CHSP good practice guide. 2015.

19. Baker DI, Gottschalk M, Eng C, Weber S, Tinetti ME. The design and implementation of a restorative care model for home care. Gerontologist. 2001;41(2):257-63.

20. Parsons J, Rouse P, Robinson EM, Sheridan N, Connolly MJ. Goal setting as a feature of homecare services for older people: does it make a difference? Age Ageing. 2012:41(1):24-9.

21. Galik EM, Resnick B, Pretzer-Aboff I. 'Knowing what makes them tick': motivating cognitively impaired older adults to participate in restorative care. Int J Nurs Pract. 2009;15(1):48-55.

22. Rabiee P, Glendinning C. Organisation and delivery of home care reablement: what makes a difference? Health \& Social Care in the Community. 2011;19(5):495-503.

23. Craig P, Dieppe P, Macintyre S, Michie S, Nazareth I, Petticrew M. Developing and evaluating complex interventions: the new Medical Research Council guidance. BMJ. 2008;337:a1655.

24. Lewin GF, Alfonso HS, Alan JJ. Evidence for the long term cost effectiveness of home care reablement programs. Clin Interv Aging. 2013:8:1273-81.

25. Low L-F, Fletcher J, Goodenough B, Jeon Y-H, Etherton-Beer C, MacAndrew $M$, Beattie $E$. A systematic review of interventions to change staff care practices in order to improve resident outcomes in nursing homes. PLoS One. 2015:10(11):e0140711.

26. Heifetz RA, Laurie DL. The work of leadership. Harv Bus Rev. 1997;75(1):124-34.

27. Kotter JP. Leading change. Boston: Harvard business review press; 2012

28. Mitchell G, Agnelli J. Person-centred care for people with dementia: Kitwood reconsidered. Nurs Stand. 2015:30(7):46-50.

29. Kim SK, Park M. Effectiveness of person-centered care on people with dementia: a systematic review and meta-analysis. Clin Interv Aging. 2017;12:381-97.

30. Bandura A. Social learning theory. Englewood Cliffs: Prentice Hall; 1977.

31. Jeon Y-H, Merlyn T, Chenoweth L. Leadership and management in the aged care sector: a narrative synthesis. Australasian Journal on Ageing. 2010;29(2):54-60.

32. Roberts T, Nolet K, Bowers B. Consistent assignment of nursing staff to residents in nursing homes: a critical review of conceptual and methodological issues. The Gerontologist. 2015;55(3):434-47.

33. Hsieh HF, Shannon SE. Three approaches to qualitative content analysis. Qual Health Res. 2005;15(9):1277-88.

34. Malley JN, Towers A-M, Netten AP, Brazier JE, Forder JE, Flynn T. An assessment of the construct validity of the ASCOT measure of social care-related quality of life with older people. Health Qual Life Outcomes. 2012;10(1):21.

35. Knight C, Haslam SA, Haslam C. In home or at home? How collective decision making in a new care facility enhances social interaction and wellbeing amongst older adults. Ageing Soc. 2010;30(08):1393-418.

36. Guralnik JM, Simonsick EM, Ferrucci L, Glynn RJ, Berkman LF, Blazer DG, Scherr PA, Wallace RB. A short physical performance battery assessing lower extremity function: Association with self-reported disability and prediction of mortality and nursing home admission. J Gerontol. 1994;49(2):M85-M94.

37. Alexopolous G, Abrams R, Young R, Shamoian C. Scale for depression in dementia. Biol Psychiatry. 1988;23(3):271-84
38. Gelinas I, Gauthier L, McIntyre M, Gauthier S. Development of a Functional Measure for Persons With Alzheimer's Disease: The Disability Assessment for Dementia. Am J Occup Ther. 1999;53(5):471-81.

39. Cohen-Mansfield H, Marx M, Rosenthal AS. A Description of Agitation in a Nursing Home. J Gerontol. 1989;44(3):M77-M84.

40. Castle NG, Engberg J, Anderson R, Men A. Job Satisfaction of Nurse Aides in Nursing Homes: Intent to Leave and Turnover. Gerontologist. 2007;47(2): 193-204.

41. Edvardsson D, Fetherstonhaugh D, Nay R, Gibson S. Development and initial testing of the Person-centered Care Assessment Tool (P-CAT). Int Psychogeriatr. 2010;22(01):101.

\section{Ready to submit your research? Choose BMC and benefit from:}

- fast, convenient online submission

- thorough peer review by experienced researchers in your field

- rapid publication on acceptance

- support for research data, including large and complex data types

- gold Open Access which fosters wider collaboration and increased citations

- maximum visibility for your research: over $100 \mathrm{M}$ website views per year

At BMC, research is always in progress.

Learn more biomedcentral.com/submissions 